\title{
MODELING AND PREDICTION OF MRR AND SURFACE ROUGHNESS IN TURNING OPERATIONS USING FACTORIAL METHOD AND REGRESSION METHOD
}

\author{
Brajesh Kumar Lodhi* \\ Mechanical Engineering Department \\ Bundelkhand Institute of Engineering \& Technology \\ Jhansi, India \\ E-mail:brajeshlodhi@gmail.com
}

\author{
Sumit Saurabh Singh \\ Mechanical Engineering Department \\ Bundelkhand Institute of Engineering \& Technology \\ Jhnasi, India \\ E-mail:sumit.biet2312@gmail.com
}

\begin{abstract}
This paper presents the findings of an experimental analysis into the effects of feed rate, cutting speed, depth of cut, and cutting environment in turning operation of Low alloy steel (En-353). Design of experiment technique, i.e. factorial method have been used to accomplish the objective of the experimental study. $2^{3}$ factorial design with eight treatment combination used for conducting the experiments. It was observed that the feed rate and depth of cut was the most influential factors on the MRR and surface roughness. The importance of the cutting parameters on the cutting performance outputs is determined by using the variance analysis (ANOVA).The variation of MRR and surface roughness with cutting parameters is modeled by using a regression analysis method.
\end{abstract}

Keywords - Turning process; MRR, Surface roughness, Factorial method, ANOVA

\section{INTRODUCTION}

Turning processes are replacing grinding for finishing various mechanical components of hardened steels such as transmission shafts, bearings and gears for the automotive industry, as well as landing gear struts for the aerospace industry. It is characterized by development of high temperatures at the cutting zone, which impairs the surface quality of the final product. Turning with multilayer coated carbide tool has several benefits over grinding process such as, reduction of processing costs, increased productivities and improved material properties [1]. Several researchers have established that hard coatings deposited on tool and machine parts by different physical vapour decomposition methods can improve the performance of the parts. These coated materials not only help reducing the wear and increasing the tool life but also improve strength and chemical inertness, reduce friction, and make the parts more stable at high temperatures. Turning is the first most common method for cutting and especially for the finishing machined parts. In a turning operation, it is important task to select cutting parameters for achieving high cutting performance. Cutting parameters are reflected on surface roughness, surface texture and dimensional deviations of the product. Surface roughness, which is used to determine and to evaluate the quality of a product, a measure of the technological quality of a product and a factor that greatly influences manufacturing cost. It describes the geometry of the machined surfaces and combined with the surface texture. Barry and Byrne [2] investigated the mechanism of AL2O3/TiC cutting tool wear in the finish turning of hardened steels with particular cognizance of the work material inclusion content. The rate of tool wear appears to be determined by the hard inclusion contend or alloy carbide content of the work material. a new mechanism is proposed to account for the superior wear resistance of $\mathrm{CBN} / \mathrm{TiC}$ composites in comparison to high-content $\mathrm{CBN}$ tools in the finish machining of 4340 (AISI) steel of 52 HRC. Hassan, K. et al. [3] has done the experimental investigation of material removal rate (MRR) in cnc turning of C34000 using taguchi method using L'27 array. When the MRR is optimized alone the MRR comes out to be 8.91 . The optimum levels of process parameters for simultaneous optimization of MRR have been identified. Optimal results were verified through confirmation experiments. It was concluded that MRR is mainly affected by cutting speed and feed rate. Jenn-Tsong et al. [4] developed RSM model using CCD in the hard turning using uncoated Al2O3/TiC mixed ceramics tool for flank wear and surface roughness. Flank wear was influenced principally by the cutting speed and the interaction effect of feed rate with nose radius of tool. The cutting speed and the tool corner radius affected surface roughness significantly. Sahin and Motorcu [5] indicated that the feed rate was found out to be dominant factor on the surface roughness, but it decreased with decreasing cutting speed, feed rate, and depth of cut in turning AISI 1050 hardened steels by CBN cutting tool. The RSM predicted and experimental surface roughness values were found to be very close. Zhang et al. [6] investigated the surface integrity of hardened bearing steel in hard turning using Taguchi method and optimized the parameter. Ozel and Karpat [7] developed regression and ANN models in finish hard turning of AISI H13 steel for surface roughness and tool wear. Decrease in the feed rate, better was the surface roughness but slightly faster tool wear development. Increasing cutting speed resulted in significant increase in tool wear development but resulted in better surface roughness. Increase in the work-piece hardness resulted in better surface roughness with higher tool wear.

In this study, the effect of the machining parameters and their levels of significance on material removal rate and surface roughness were statistically evaluated by using analysis of variance (ANOVA). Experiments were conducted under different machining parameters namely, feed rate, speed and depth of cut. The setting of maching parameters was determined by using factorial method. The factorial parameter design in order to identify the optimum material removal rate and surface roughness performance with a particular combination of cutting parameters in a turning operation. 


\section{EXPERIMENTATION}

\section{A. Experimental Set-up and Material}

In the present study, Low alloy steel EN 353 grade ( $25 \mathrm{~mm}$ diameter, $152 \mathrm{~mm}$ long) is selected. The properties of EN 353 steel work-piece material, used for experimentation in this work, are as given in Table 1. The parameters, chosen for different settings of feed rate (A), Depth of cut (B) and speed (C) were used in the experiments. The cutting tool selected were titanium coated carbide inserts (TN4000) of corner radius $0.800 \mathrm{~mm}$. Fig. 1 shows the schematic diagram and the setup of turning process.

TABLE I.

(WT\%)

CHEMICAL COMPOSITION OF EN-353 STEEL

\begin{tabular}{|c|c|c|c|c|c|c|c|}
\hline Material & $\mathrm{C}$ & $\mathrm{Si}$ & $\mathrm{Cr}$ & $\mathrm{Mn}$ & $\mathrm{Ni}$ & $\mathrm{Mo}$ & $\mathrm{S}$ \\
\hline $\mathrm{Fe}-703$ & 0.40 & 0.21 & 0.53 & 0.34 & 0.03 & 0.22 & 0.027 \\
\hline
\end{tabular}

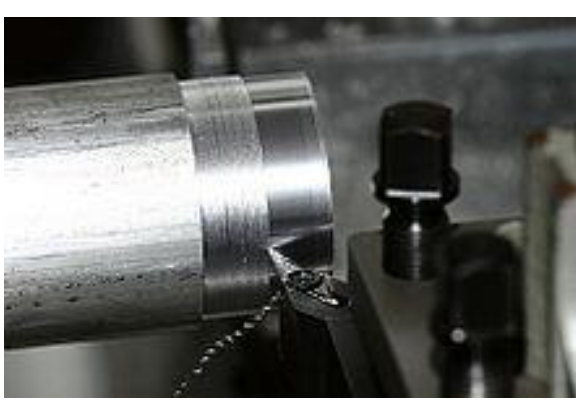

Fig. 1. Experimental setup Turning Process

TABLE II.

PARAMETERS AND THEIR LEVELS

\begin{tabular}{|c|c|c|c|c|}
\hline \multirow{2}{*}{ Parameters } & \multirow{2}{*}{ Symbol } & \multirow{2}{*}{ Unit } & \multicolumn{2}{|c|}{ Level } \\
\cline { 4 - 5 } & & & $\mathbf{( - 1 )}$ & $\mathbf{( + 1 )}$ \\
\cline { 4 - 5 } & & & 0.05 & 0.10 \\
\hline Feed rate & $\mathrm{A}$ & $\mathrm{mm} / \mathrm{rev}$ & High \\
\hline Depth of cut & B & $\mathrm{mm}$ & 0.25 & 0.5 \\
\hline Speed & C & rpm & 710 & 1120 \\
\hline
\end{tabular}

There are various process parameters of $\mathrm{CNC}$ lathe affecting the material removal rate and surface roughness. On the basis of pilot run investigations, the following process parameters have been selected for study. Their levels are given in Table 2.

\section{B. Measurment}

The material removal rate (MRR) in turning operations is the volume of material/metal that is removed per unit time in $\mathrm{mm}^{3} / \mathrm{min}$. For each revolution of the work piece, a ring shaped layer of material is removed.

$$
\operatorname{MRR}=
$$

Where, $\mathrm{Wa}=$ after maching weight of work piece in $\mathrm{gm} \mathrm{Wb}=$ before machining weight of work piece in $g m t=$ Machining time in seconds $\rho=$ Density of EN-353 steel $=\left(7.9 \times 10^{-3}\right.$ $\left.\mathrm{gm} / \mathrm{mm}^{3}\right)$.
Surface roughness measurements have been done using a Stylus type roughness tester. Surface roughness measurements are taken on the work-piece in the transverse direction and this procedure repeated three times to obtain the average value of surface roughness and all he measurements of surface roughness cut-off length is taken as $0.8 \mathrm{~mm}$.

\section{Factorial Method}

In a factorial experiment, the effect of varying the level of the various factor affecting the process output are investigated. Each complete trial replication of the experiment takes into account all the possible combination of the varying level of these factors effective factorial design ensures that the least no. of the experiment runs are conducted to generate the maximum amount of information about input variable effect the output of process (Table 3) [8].

TABLE III DESGIN OF THE EXPERIMENTS AND RESULTS

\begin{tabular}{|l|c|c|c|c|c|}
\hline \multirow{2}{*}{ Sr. No. } & $\mathbf{A}$ & $\mathbf{B}$ & $\mathbf{C}$ & $\mathbf{M R R}$ & $\mathbf{R a}$ \\
\cline { 2 - 6 } & $\mathbf{m m} / \mathbf{r e v}$ & $\mathbf{m m}$ & $\mathbf{r p m}$ & $\mathbf{m m}^{3} \mathbf{m i n}$ & $\boldsymbol{\mu m}$ \\
\hline 1 & -1 & -1 & -1 & 697 & 2.20 \\
\hline 2 & +1 & -1 & -1 & 1394 & 3.00 \\
\hline 3 & -1 & +1 & -1 & 1594 & 3.50 \\
\hline 4 & +1 & +1 & -1 & 2788 & 3.97 \\
\hline 5 & -1 & -1 & +1 & 1100 & 1.08 \\
\hline 6 & +1 & -1 & +1 & 2175 & 1.39 \\
\hline 7 & -1 & +1 & +1 & 2199 & 2.60 \\
\hline 8 & +1 & +1 & +1 & 3898 & 3.4 \\
\hline
\end{tabular}

\section{RESULT AND DISSCUSSION}

After all test are conducted, decisions must be made confirming parameters affect the performance such as MRR and surface roughness and after that access to a mathematical model how can predict value amount close to the actual values. The effect of process parameters on the material removal rate and is shown in Fig.2. The MRR of the work pieces increases with increase in depth of cut as well as feed rate. Effect of depth of cut on the surface roughness as well as MRR is more in comparison to feed rate.

The effect of process parameters on the surface roughness and is shown in Fig.3. The surface roughness of work piece is increased with increase in depth of cut as well as feed rate, because of increase in net resistance material. Thus the size of removed material is big so the surface roughness of work piece material is increased.

These plots are used to visuliaize the relation between parameters ant output response. Since analysis of the results the parameters at spindle speed (level +1$)$, feed rate $($ level +1$)$, depth of cut $($ level +1$)$ gives the maximum MRR and spindle speed (level +1 ), feed rate (level -1), depth of cut (level -1) gives the minimization of surface roughness. 
Asia Pacific Journals

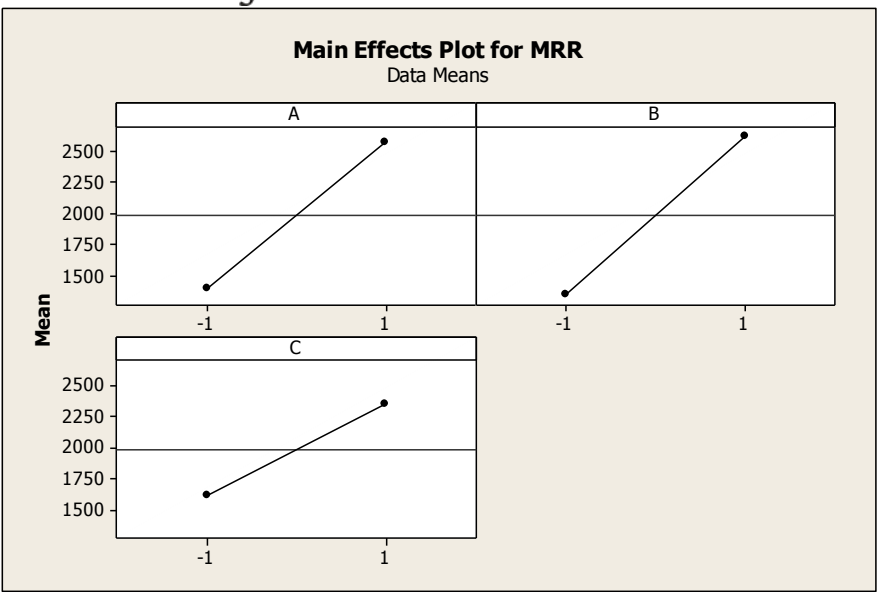

Fig. 2. Effect of parameters on MRR

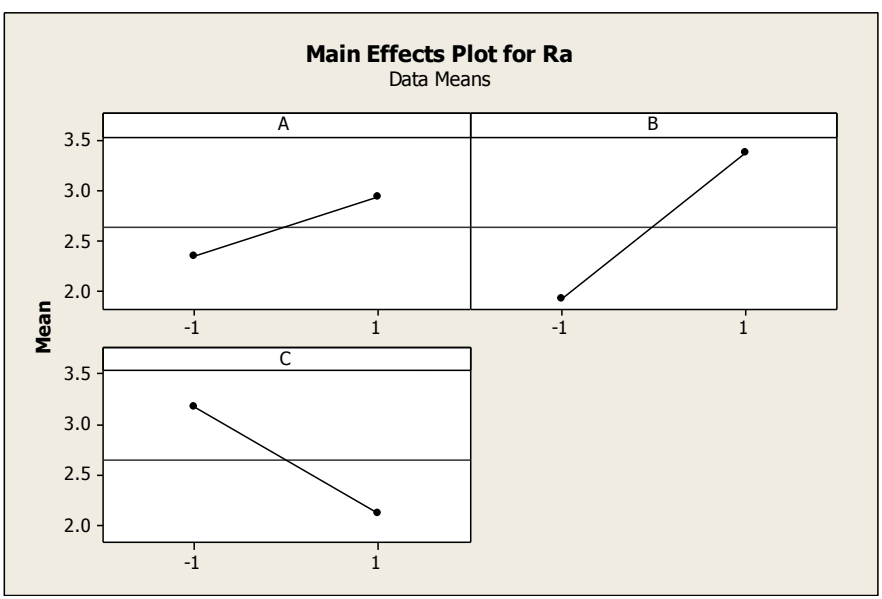

Fig. 3. Effect of parameters on Surafce Roughness

\section{A. Normal Probability Plot}

The normal probability plot is a graphical technique to identify substantive departures from normality. This includes identifying outliers, skewness, kurtosis, a need for transformations, and mixtures. Normal probability plots are made of raw data, residuals from model fits, and estimated parameters. In a normal probability plot (also called a "normal plot"), the sorted data are plotted vs. values selected to make the resulting image look close to a straight line if the data are approximately normally distributed. Deviations from a straight line suggest departures from normality. Hence, it is proved, this experiment follow the normality assumption. The normal probability plots of residuals are shown in Fig.4 and Fig.5 for material removal rate (MRR) and Surface roughness (Ra) respectively [8].

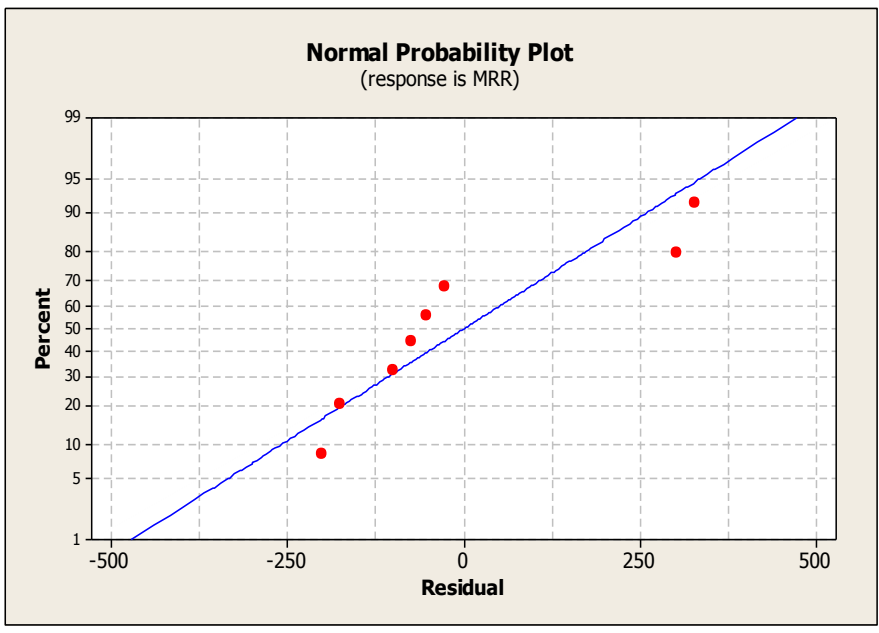

Fig. 4. Normal Probability plot for MRR

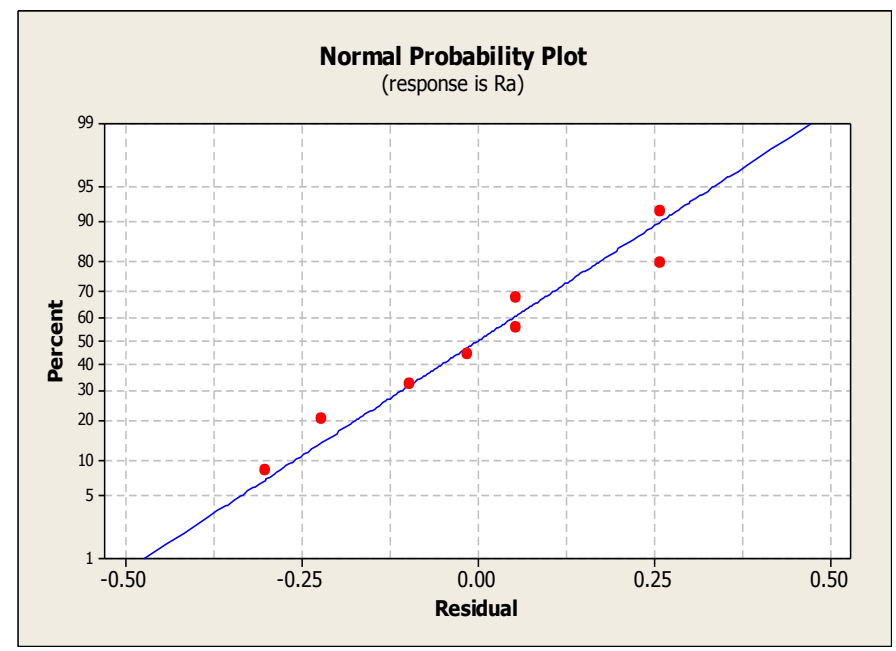

Fig. 5. Noraml probability plot for Ra

\section{B. Analysis of Variance (ANOVA)}

ANOVA is a statically based, objective decision making tool for detecting any differences in average performance of groups of items tested [9]. An ANOVA table consists of sum of squares, corresponding degree of freedom, the F-ratio corresponding to the ratios of two mean squares, and the contribution proportions from each of the control factors. These contribution proportions can be used to assess the importance of each factor for interested multiple performance characteristics (MPCs). The total sum of squares, $\mathrm{SS}_{\mathrm{T}}$, in the ANOVA is:

$$
S_{T}={ }^{2}
$$

This can be reduced to the following forms:

\section{$S$}

Following a similar approach, the variation caused by an individual parameters, say $\mathrm{A}$, is obtained an expression called the parameters sum of square as

$$
S S=\frac{A_{1}^{2}}{N_{A 1}}+\frac{i}{N}
$$




\section{Asia Pacific Journals}

Where C.F. is the correction parameters $(=\quad), \mathrm{N}_{\mathrm{A} 1}$ the total number of experiments in which level 1 of parameters $A$ is present, and $A_{1}$ the total results $Y_{1}$ that parameters $A_{1}$.

The total and parameters sum of square are the basic calculation needed for ANOVA table. Three another quantities calculated as parts of ANOVA table information are all derived from the original Sum of squares for factor A, they are follows:

$$
\begin{aligned}
& \text { Mean Square MS }= \\
& \text { F - Ratio } \mathrm{F}_{\mathrm{A}}= \\
& \text { Percentage Influence }=\frac{\text { Sum of } \Im \mathrm{c}}{\text { Total Sur }}
\end{aligned}
$$

The total degrees of freedom needs to be computed an appropriate orthogonal array for the experiments. The degrees of freedom are defined, as the number of comparisons that needs to be made to determine which level is better.

Total DOF $=$ Number of experiments -1

Factors DOF $=$ Number of levels -1

Error term of DOF $=$ Total DOF - Sum of all Factors DOF

TABLE IV ANOVA FOR MATERIAL REMOVAL RATE

\begin{tabular}{|c|c|c|c|c|c|}
\hline Factors & DOF & SS & MS & $\begin{array}{c}\boldsymbol{F} \text { - } \\
\text { Value }\end{array}$ & $\boldsymbol{P} \%$ \\
\hline A & 1 & 2748340 & 2748340 & 38.3 & 37.44 \\
\hline B & 1 & 3237240 & 3237240 & 45.1 & 44.10 \\
\hline C & 1 & 1067991 & 1067991 & 14.9 & 14.54 \\
\hline Error & 4 & 286715 & 71679 & & 3.91 \\
\hline Total & 7 & 7340286 & & & 100 \\
\hline
\end{tabular}

TABLE V ANOVA FOR SURFACE ROUGHNESS

\begin{tabular}{|c|l|c|c|c|c|}
\hline Factors & DOF & SS & MS & $\begin{array}{c}\boldsymbol{F} \text { - } \\
\text { Value }\end{array}$ & $\boldsymbol{P} \%$ \\
\hline A & 1 & 0.7080 & 0.7080 & 9.80 & 9.55 \\
\hline B & 1 & 4.2050 & 4.2050 & 58.22 & 56.77 \\
\hline C & 1 & 2.2050 & 2.2050 & 30.53 & 29.76 \\
\hline Error & 4 & 0.2889 & 0.0722 & & 3.90 \\
\hline Total & 7 & 7.4069 & & & 100 \\
\hline
\end{tabular}

According to F-test analysis, the significant parameters on the MRR are depth of cut and feed rate (TABLE IV). Depth of cut is found to be the major factor affecting the MRR $(44.10 \%)$. The percent contributions of feed rate and speed for MRR are 37.44 and $14.54 \%$, respectively. Similarly, According to F-test analysis, the significant parameters on the $\mathrm{Ra}$ are depth of cut (TABLE V). Depth of cut is found to be the major factor affecting the MRR (58.22\%). The percent contributions of feed rate and speed for MRR are 9.55and $29.76 \%$, respectively

\section{REGRESSION ANALYSIS}

In any machining process, a mathematical model has to be developed relating the machining output to be machined parameters. Then other developed model can be used for prediction, process control or optimization [8]. In order to evaluate the effect of cutting parameters of turning process in terms of cutting performance such as surface roughness of the machined work-piece and the amount of material removed, a factorial method coupled with Multiple Linear Regression (MLR) analysis is applied here to model the Turning process. Based on the analysis, select the optimal parameters and effects and conform the mathematical equation for each performance characteristics to suitable coefficients. The mathematical model can be written here in following form.

$$
Y=b_{0}+b_{1} x_{1}+b_{2} x_{2}+\ldots+b_{k} x_{k}
$$

Where $\mathrm{Y}$ is the Performance output in term (MRR and surface roughness) and $b_{i}$ is the regression coefficient for regressor factor. The value of these constants can be calculated by using non-linear regression analysis method with the help of MINITAB-15 software.

$\operatorname{MRR}\left(\mathrm{mm}^{3} / \mathrm{min}\right)=1983.63+586.125$ Feed rate +636.125 Depth of cut +365.375 Speed, $r^{2}=96.09$

$R a(\mu m)=2.6425+0.2975$ Feed rate +0.725 Depth of cut 0.525 Speed, $r^{2}=96.10$

The results indicates that the estimated regression model is significant at the $\alpha$-level of $0.05 \mathrm{R}$-squared $\left(\mathrm{R}^{2}\right)$ amount was calculated to check the goodness of fit. The $\mathrm{R}^{2}$ value indicates that the predictor explain $96.09 \%$ and $96.10 \%$ of the response variation for MRR and Ra width respectively. Adjusted $\mathrm{R}^{2}$ for the number of predictors in the model was $93.16 \%$ (MRR) and $93.17 \%$ (surface roughness). Both values show that data are fitted well.

\section{CONFIRMATION EXPERIMENT}

Confirmontory experimnt are carried out at the parameters settings corresopnding to maximum material removal rate and minimum surafce rougness inTable 6 , check the validity of the optimization results.

TABLE VI.

OPTIMAL MACHINING PARAMETERS

\begin{tabular}{|c|c|c|c|c|c|}
\hline Response & \multicolumn{3}{|c|}{$\begin{array}{l}\text { Optimal machining } \\
\text { parameters }\end{array}$} & Prediction & Experiment \\
\hline \multirow{2}{*}{ MRR } & $\begin{array}{c}\mathrm{A} \\
(+)\end{array}$ & $\begin{array}{c}\mathrm{B} \\
(+)\end{array}$ & $\begin{array}{c}\mathrm{C} \\
(+)\end{array}$ & $\begin{array}{c}3898 \\
\mathrm{~mm}^{3} / \mathrm{min}\end{array}$ & $\begin{array}{c}4010 \\
\mathrm{~mm}^{3} / \mathrm{min}\end{array}$ \\
\hline $\mathrm{Ra}$ & $\begin{array}{c}\mathrm{A} \\
(-)\end{array}$ & $\begin{array}{c}\mathrm{B} \\
(-)\end{array}$ & $\begin{array}{c}\mathrm{C} \\
(+)\end{array}$ & $1.08 \mu \mathrm{m}$ & $1.10 \mu \mathrm{m}$ \\
\hline
\end{tabular}




\section{Asia Pacific Journals}

The results of experimental confirmation using optimal machining parameters are shown in Tables 6 . From the above observations, it can be interpreted that the obtained MRR and $\mathrm{Ra}$ have reasonable accuracy for resulting model because an error of $2.79 \%$ and $1.81 \%$ respectively. It is observed from Table 6 that the error between the predicted and experimental results is less than, which confirm the good reproducibility of the results.

\section{CONCLUSION}

The effect of Turning process parameters in terms of material removal rate and surface roughness of Low alloy steel (EN-353), using Factorial Method. Based on the experimental results and analysis, the following conclusions can be

For maximum material removal rate and minimum surface rouhness optimal combination of process parameters are feed rate $(0.10 \mathrm{~mm} / \mathrm{rev})$, depth of cut $(0.5 \mathrm{~mm})$, speed $(1120 \mathrm{rpm})$ and feed rate $(0.05 \mathrm{~mm} / \mathrm{rev})$, depth of cut $(0.25 \mathrm{~mm})$, speed (1120rpm) respectively.

Depth of cut (B) and feed rate (A) contributes most significantly towards MRR and Surface roughness as the difference value is highest, followed speed.

Experimental value $4010 \mathrm{~mm}^{3} / \mathrm{min}$ for MRR is very close to the predicted $3898 \mathrm{~mm}^{3} / \mathrm{min}$ and Experimental value $1.10 \mu \mathrm{m}$ for surface roughness is very close to the predicted $1.08 \mu \mathrm{m}$. It shows very good reproducibility and confirms the success of the experiments.
The confirmation experiments shows that the error associated with MRR and surface roughness is 2.79 $\%$ and $1.81 \%$ respectively.

\section{References}

[1] P.G. Benardos, G.C. Vosniakos, "Predicting surface roughness in machining: a review," International Journal Machine Tools \& Manufacturer, vol. 43, pp. 833-844, 2003.

[2] J. Barry, G. Bryne, "Cutting tool wear in the machining hardended steels-Part II: cubic boron nitride cutting tool wear,” Wear, vol. 247(2), pp. 152-60, 2001 .

[3] K. Hassan,"Experimental investigation of material removal rate in CNC turning using Taguchi method", International Journal of Engineering Research and application, Vol. 2, pp. 1581-1590, 2012.

[4] H. Jenn-Tsong, L. Nun-Ming, C. Ko-Ta, "Investigating the machinability evaluation of hadfield steel in the hard turning with $\mathrm{Al} 2 \mathrm{O} 3 / \mathrm{TiC}$ mixed ceramic tool based on the response surface methodology," Journal of Materials Processing Technology, Vol. 208, 532-541, 2008.

[5] Y. Sahin, A.R. Motorcu, "Surface roughness model in machining hardened steel with cubic boron nitride cutting tool," International Journal of Refractory Metals and Hard Materials, Vol. 26, pp. 84 90,2008 .

[6] X.P. Zhang, C. Richard Liu, Y. Zhenqiang, "Experimental study and evaluation methodology on hard surface integrity," International Journal of Advanced Manufacturing Technology, Vol. 34, pp. 141-148, 2007.

[7] T. Ozel, Y. Karpat, "Predictive modeling of surface roughness and tool wear in hard turning using regression and neural networks," International Journal of Machine Tools and Manufacture, Vol. 45, pp. 467-479, 2005.

[8] D.C. Montgomery: Design and Analysis of Experiments, John Wiley and Sons, Singapore, 1991.

[9] P.J. Ross, Taguchi Techniques for Quality Engineering, Tata McGrawHill, New York, 1996. 